\title{
Living Arrangements and Children's Development in Low-Income White, Black, and Latino Families
}

\author{
E. Michael Foster \\ University of North Carolina-Chapel Hill
}

\author{
Ariel Kalil \\ University of Chicago
}

\begin{abstract}
This article uses longitudinal data from approximately 2,000 low-income families participating in the national evaluation of the Comprehensive Child Development Program to examine the associations between preschool children's living arrangements and their cognitive achievement and emotional adjustment. The analysis distinguishes families in which children live only with their mothers from children who live in biological father, blended, and multigenerational households. Linkages are examined separately for White, Black, and Latino children. Fixed effects regression techniques reveal few significant associations between living arrangements and child development. These findings suggest that substantial diversity exists in the developmental contexts among children living in the same family structure. Policies seeking to change the living arrangements of low-income children may do little to improve child well-being.
\end{abstract}

Young low-income children experience diverse living arrangements. As is well known, the number of children born to unmarried mothers has increased dramatically in the past 20 years. Between 1980 and 2003, the percentage of births to unmarried women rose from $18 \%$ to $35 \%$ (Federal Interagency Forum on Child and Family Statistics, 2005). Further, these figures vary widely by race/ethnicity: In 2003, $69 \%$ of births to Black women were to unmarried mothers compared to $45 \%$ of births to Hispanic women and $24 \%$ to White women.

Children born to unmarried mothers have been in the public policy spotlight due, among other things, to their high rates of poverty and welfare use. In 2003, the poverty rate for children living with only their mother was nearly five times that for children living in married-couple families (42\% vs. 9\% [Federal Interagency Forum on Child and Family Statistics, 2005]). In response, the current federal administration is spending \$150 million annually for healthy marriage promotion and fatherhood programs (U.S. Department of Health and Human Services [DHHS], 2006).

Such government initiatives not only assume that marriage is a marker for childhood disadvantage, but they also assume that the fact that parents did not marry is the underlying cause of their offspring's

Support for this work was provided in part by a grant from the National Institute for Child Health and Human Development (\#R01 HD40935-01). We thank E. J. Kang for research assistance and Kathleen M. Ziol-Guest, Miao Jiang, and Cindy Chambers for editorial assistance. We also thank Christina Gibson-Davis for thoughtful comments on an earlier draft.

Correspondence concerning this article should be addressed to E. Michael Foster, School of Public Health, University of North Carolina, Chapel Hill, Rosenau Hall, Campus Box \#7445, Chapel Hill,NC 27599-7445. Electronic mail may be sent to emfoster@unc.edu. problems. Distinguishing these two possibilities empirically is difficult. Various aspects of disadvantage shape both living arrangements and child outcomes, and those factors confound the effect of the former on the latter. Policy decisions depend on causal inferencespublic policies aim to change aspects of the child's developmental environment in order to cause changes in key outcomes. Yet, few developmental studies have focused on whether any observed "effects" of living arrangements can plausibly be characterized as causal (but see Dunifon \& Kowaleski-Jones, 2002).

The purpose of the present study was to compare the development of children living with only their mothers (henceforth "mother-only" household) with children in other arrangements using statistical techniques that produce regression coefficients that are more likely to capture the effect of living arrangements on child outcomes than conventional regression models. We attend not only to the variety of living arrangements among children living with their mother but not their father but also to variation in associations of living arrangements with developmental outcomes separately for children of different racial and ethnic backgrounds.

\section{Background}

Considerable research documents that children growing up with two biological married parents have access to greater economic, social, and psychological resources (McLanahan \& Sandefur, 1994). Thus, perhaps not

(C) 2007 by the Society for Research in Child Development, Inc. All rights reserved. 0009-3920/2007/7806-0003 
surprisingly, research often has shown that not growing up in this type of household is associated with negative consequences for children. Much early work in this area compared children in mother-only households to those in biological married-parent households and found relatively poorer outcomes among the former across a range of outcomes (McLanahan \& Sandefur, 1994). Dunifon and Kowaleski-Jones (2002), however, showed that living in a mother-only household was associated with lower levels of well-being for White children but not Black children.

The literature on child well-being in blended families (i.e., one biological and one nonbiological parent) provides generally consistent evidence that these children also do not fare as well as those living with two biological married parents; rather, children in blended families have outcomes similar to those in mother-only households (Brown, 2004; Deleire \& Kalil, 2002; Dunifon \& Kowaleski-Jones, 2002; Fortney, Booth, Zhang, Humphrey, \& Wiseman, 1998; Ganong \& Coleman, 2004; Hofferth \& Anderson, 2003; Nelson, Clark, \& Acs, 2001; Osborne, McLanahan, \& Brooks-Gunn, 2003), although again, in some studies, this appears to be less true for Black children than for White or Latino children (Hall et al., 2001; McLanahan \& Sandefur, 1994; Nelson et al., 2001). Researchers have found few differences between children in married versus unmarried blended families (Brown, 2004; Nelson et al., 2001).

The empirical evidence assessing child development in multigenerational households is somewhat mixed. Young Black children in multigenerational households have better school conduct and higher grades in reading relative to Black children who live in mother-only households (Entwisle \& Alexander, 1996; Thompson, 1992). Similarly, teenage children who ever lived in a multigenerational household during childhood exhibit higher educational attainment than do their counterparts in mother-only households (Aquilino, 1996; Ricciuti, 2004). However, in studies of very young mothers, some (Conrad et al., 1998; Leadbeater \& Bishop, 1994) find positive effects on child development and others (East \& Felice, 1996; Unger \& Cooley, 1992) find negative effects on the same outcomes. Under certain circumstances, multigenerational arrangements are associated with poorer parenting behaviors in the home (Chase-Lansdale, Brooks-Gunn, \& Zamsky, 1994).

\section{Theoretical Pathways Linking Living Arrangements and Child Development}

Researchers have not reached a consensus as to why and how living arrangements might matter. Four theories prevail: economic deprivation, socialization, stress, and community resources (Haurin, 1992; McLanahan \& Sandefur, 1994). These theories typically have been used to explain developmental differences between children in mother-only households and those in biological married-parent households. The economic deprivation perspective argues that poverty and associated economic conditions explain variation in child development across living arrangements. McLanahan and Sandefur (1994) found that family economic resources account for about one half of the differences in child developmental outcomes between mother-only households and biological married-parent households. The socialization perspective (also discussed in McLanahan \& Sandefur, 1994) suggests that two parents provide an optimal childrearing environment and that children benefit from the presence of a male role model in a two-parent home (see Kalil, DeLeire, Jayakody, \& Chin, 2001 for a discussion pertaining to low-income families). Third, community and out-of-home resources, such as the characteristics of the family's neighborhood and the child's school or day care arrangements, may vary across living arrangements and have an impact on children's development (McLanahan \& Teitler, 1999). Finally, the stress perspective emphasizes the effects of transitions in living arrangements, which are hypothesized to disrupt relationships within and outside the family as well. The accumulation of these changes is posited to produce poor developmental outcomes among children (Aquilino, 1996; Wu, 1996). All four of these mechanisms point to the advantages of living in a married-parent household.

\section{Demographic Differences in Living Arrangements Across Race/Ethnic Groups}

Demographers have long recognized the diversity of children's living arrangements, but developmental studies have been slower to incorporate these distinctions. This diversity is especially important for understanding racial and ethnic variation in the prevalence and impact of low-income children's living arrangements. In particular, living apart from one's biological father in a married-parent household often means rather different living arrangements for ethnic minority compared to White children.

In $2002,12 \%$ of White children, $15 \%$ of Latino children, and $36 \%$ of Black children lived in a mother-only household (Wherry \& Finegold, 2004). In contrast, $69 \%$ of White children, $55 \%$ of Latino children, and $27 \%$ of Black children lived with two married biological parents; an additional $2 \%$ of White children, $7 \%$ of Latino children, and 3\% of 
Black children lived with two biological parents who were not married to each other (Wherry \& Finegold, 2004, see also Kreider \& Fields, 2005, for similar estimates). In 2001, only $2 \%$ of White children lived with only their mother and a grandparent compared to $5 \%$ of Latino children and $7 \%$ of Black children (Kreider \& Fields, 2005). Remarriage following a divorce is more common for White parents than for Black parents (Glascoe, Foster, \& Wolraich, 1997); blended families can also be formed when mothers marry for the first time following a nonmarital birth, although this too is less likely for Black and Latino children born to unmarried mothers than for their White counterparts (Bzostek, Carlson, \& McLanahan, 2007).

The Social and Economic Meanings of Living Arrangements Across Race/Ethnic Groups

Differences in the prevalence of different living arrangements across race and ethnic groups provide one reason to expect that their linkages to child development outcomes might also differ. In other words, if certain family forms are substantially more common in one group than in others, one might expect that their social meaning in families' lives may also differ. Latinos, for example, have a long history of consensual or informal unions (Lichter \& Qian, 2004) and have, in broad terms, been described as having a familistic cultural orientation (Baca Zinn, 1994; Battle, 2002; Oropesa \& Landale, 2004). Familism encompasses values supporting marriage and fertility as well as maintaining relationships with nuclear and extended families and is generally viewed as protective (Baca Zinn, 1994; Oropesa \& Landale, 2004; Raley, Durden, \& Wildsmith, 2004). Some studies suggest that Latinos are more likely than Blacks or Whites to consider cohabitation as an acceptable childrearing context (Smock, 2000).

The social meaning of different living arrangements to families of different race and ethnic backgrounds is also likely influenced by the range of risk and protective factors that correlate with particular living arrangements and that also differ across groups. Key factors including employment, economic circumstances, family processes, and neighborhood location may dampen or amplify the effects of different living arrangements on children's development.

In general, White single mothers fare better economically than their non-White counterparts. Given that employment is the most important source of income for most Americans, differences in employment opportunities could produce differences in family income, which may in turn produce differ- ences in child well-being (Duncan \& Brooks-Gunn, 1997). The employment rate for White single mothers in the year 2000 was $75 \%$ compared to $70 \%$ for Black single mothers and $64 \%$ for Latina single mothers (Sherman, Fremstad, \& Parrott, 2004). In turn, the median family income of White single mothers $(\$ 30,062)$ in 2000 was substantially greater than that of Black $(\$ 20,975)$ and Latino $(\$ 21,599)$ single mothers; Black and Latino families headed by single mothers are also about twice as likely to be poor as their White counterparts (Joint Center for Political and Economic Studies 2004). Finally, there are striking race/ethnic differences in net worth and financial assets, even in the lowest income bracket. Shapiro (2004) reported that in the bottom income quintile, Whites have median net financial assets of $\$ 7,400$, whereas Blacks' median net assets in this income group total only $\$ 100$.

Low income, especially deep and sustained poverty, has been shown to depress children's development on a range of indicators (Duncan \& BrooksGunn, 1997; McLoyd, 1998), and family wealth and assets are important buffers against the ill effects of job loss, unemployment, and income instability (Foster \& Kalil, 2005). Assessing these economic differences, one might expect that Black and Latino children living in mother-only households would be at greater risk than their White counterparts, given the deep economic disadvantages they face, and thus that these children would have the most to gain (especially in terms of escaping from poverty) if they were to live with two parents or caregivers.

However, complicating matters is the fact that marriage confers fewer economic benefits to Black and Latina women. Twenty-one percent of Latino children in married-parent families lived in poverty in 2003 compared to $11 \%$ of Black children and $5 \%$ of White children in married-parent families (Federal Interagency Forum on Child and Family Statistics, 2005). Thus, Black and Latino children may benefit less from marriage if economic conditions are a prime predictor of child development. Research also suggests that Black and Latina mothers in blended or extended households receive fewer economic benefits from this arrangement compared to their White counterparts (Manning \& Smock, 1997).

Economic inputs are not the only important ones into child development, however. The presence of a biological father or another caregiver may be important for the socialization that it provides (Kalil et al., 2001; McLanahan \& Sandefur, 1994). Here again, though, which living arrangement for children in different race/ethnic groups will yield the biggest impact is not entirely clear. Parenting occurs within 
and interacts with cultural and social contexts; there is thus ample reason to think that socialization practices will differ across White, Black, and Latino families, even among those in the same living arrangement (Garcia-Coll et al., 1996; Hofferth, 2003; Hofferth \& Anderson, 2003). Hofferth reported that compared to White fathers in two-parent families with young children, Black children's fathers exhibit less warmth and engagement but more monitoring, whereas Latino fathers monitor their children less than do White fathers. Compared to Whites, Black and Latino fathers exhibit more "responsibility" for childrearing, characterized by the amount of care they take for the child's welfare. These differences are in part a function of between-group differences in economic circumstances, neighborhood factors, and cultural factors, such as fathering and gender role attitudes.

The higher prevalence of multigenerational households among Latino and Black children has been discussed extensively in prior work with respect to a cultural emphasis on kinship ties as well as a response to economic hardship among ethnic minority families (Billingsley, 1992; Goldscheider \& Bures, 2003; Raley, 1995; Raley et al., 2004; Stack \& Burton, 1993; Wollack, Bolt, Cohen, \& Lee, 2002). Historically, Black grandmothers have been an integral part of the family system and have functioned in an interactive role (Chatters, Taylor, \& Jackson, 1985). Researchers have discussed a variety of beneficial influences of multigenerational arrangements, especially for early childbearers in Black families (see also Burton, 1996; Geronimus, Korenman, \& Hillemeier, 1994; Stack \& Burton, 1993). In contrast, Hawkins and Eggebeen (1991) described research conceptualizing the three-generation White family as aberrantneither expected nor preferred by its members due to its violation of White family norms of independence. Thus, one might expect multigenerational arrangements to confer benefits (relative to motheronly living arrangements) for Black and Latino children but not for Whites. Indeed, drawing on national longitudinal data, Deleire and Kalil (2002) reported that low-income Black eighth graders living in a multigenerational household had developmental outcomes equal to or superior to those of their counterparts living with married parents. This finding suggests that in some low-income families, a grandparent may be an equally or even more effective second caregiver than a spouse.

Finally, theoretical models of living arrangements and child well-being discuss the importance of community and neighborhood contexts (McLanahan \& Sandefur, 1994). Compared to White families, minority families experience more disadvantaged neigh- borhood environments along such dimensions as exposure to violence and community resources (Furstenberg, Cook, Eccles, Elder, \& Sameroff, 1996), both of which are associated with children's development (Aisenberg, 2001; Gorman-Smith \& Tolan, 1998; Jargowsky, 1997). Thus, if the key reason that children in mother-only households fare more poorly than their counterparts with two caregivers is due to the lack of a father or another adult to protect or shield children from dangers in their social environments, then Black and Latino children again, may have more to gain (relative to White children) from the presence of such a person, given that they live in the riskiest and least safe neighborhoods.

\section{Measuring the Causal Effects of Living Arrangements}

A key issue spanning these different perspectives is the problem of identifying the causal effect of living arrangements. The question facing policymakers is how children would fare if their living arrangements could somehow be changed. The effect of living arrangements per se is likely confounded with that of other factors, that is, those that led the adults involved to form different relationships in the first place. Some have posited that parents who cannot make and maintain a commitment to a spouse also may have a hard time developing and maintaining a strong attachment to their children (Mayer, 1997). Often drugs, alcohol, and emotional problems result in unstable relationships between partners, and these factors also affect relationships with children (Edin \& Kefalas, 2004). The present study controls for a wide range of observable characteristics to address selection bias. Yet, no list of covariates, however extensive, is likely to control for all potential confounding factors, many of which are difficult to measure. For that reason, we use fixed effects estimation as a means of capturing these factors; this technique is described in greater detail in the next section.

\section{Method}

\section{The Comprehensive Child Development Project}

Data for these analyses were collected as part of a large, multisite study of low-income women and their children. These data were collected to evaluate the Comprehensive Child Development Project (CCDP), a multicomponent intervention begun in 1990 and designed to reduce the likelihood that children from low-income families are caught in a cycle of poverty (St.Pierre, Layzer, Goodson, \& 
Bernstein, 1997). The goals of the intervention were to improve child outcomes, including cognitive development, socioemotional and behavioral functioning, and birth outcomes for newborn children. The intervention also sought to improve a mother's ability to contribute to the overall development of her child and to achieve economic self-sufficiency. At the time of recruitment (1990), $44 \%$ of households in the sample had a total income under $\$ 5,000$ and $85 \%$ had a total income under $\$ 10,000$. Thirty-five percent of the mothers in the sample were teenagers when they first gave birth and $51 \%$ had not graduated from high school at the time of recruitment (St.Pierre et al., 1997).

Within this general framework, 21 participating sites developed a web of services that reflected the availability of services in the community as well as the needs of participating mothers. (The sites were Albuquerque, Baltimore, Boston, Brattleboro, Brooklyn, Denver, Fort Totten, Fort Worth, Glenwood City, Grand Rapids, Kansas City, Las Cruces, Lexington, Little Rock, Logan, Marshalltown, Nashville, Phoenix, Pittsburgh, San Antonio, Seattle, Venice, and Washington, DC.) Case managers served as the hub of service delivery at all sites; yet, sites varied in whether case managers or a separate specialist provided the early childhood education component of the intervention. The U.S. DHHS took a number of steps to ensure that the program was high in quality, such as providing technical assistance. Using a variety of mechanisms, including site visits and compliance reports, DHHS monitored sites to ensure that no sites strayed very far from the intervention's principles. The evaluation suggested that the overall impact of the intervention was modest and short-lived; the program had no meaningful impacts on mothers' economic self-sufficiency or parenting skills, on household composition, or on the cognitive or socioemotional development of participating children (St.Pierre et al., 1997).

The data collected as part of that study represent a rich source of data on poor women and children. In particular, the data included include women in a variety of communities and include more than 100 different outcome measures for mothers and focal children. As a result, the study provides a valuable opportunity to examine the link between living arrangements and child outcomes in economically disadvantaged households.

\section{Recruitment and Data Collection}

A total of 4,410 families were recruited for a longitudinal study in 1990. To be eligible for the study, a family must have been poor, have included a preg- nant woman or child under age 1 , and have agreed to participate in the study for 5 years (St.Pierre et al., 1997). Families began receiving services in 1990, and data collection for the study began in 1991 and continued through 1996. Thirty-nine percent of participating mothers were recruited for the study before their baby was born. Among the remaining families, the participating child was roughly 5 months old at the time of recruitment.

Data collection for the study focused on the mother and the target child (though some additional information was collected on other children in the household as well as the child's father and the mother's partner). Interviews were conducted in the participant's language; $91 \%$ of the interviewers were conducted in English, with Spanish accounting for the vast majority of the remaining interviews. Interviews generally occurred on an annual basis in the family's home and continued through 1996.

Study interviews were conducted annually and were timed according to the child's second, third, fourth, and fifth birthdays. Because a fair number of children had turned 2 by the time data collection began, age 2 data are available for only $60 \%$ of the sample. Study retention was fairly good, especially given the low socioeconomic status of participating families. Roughly $75 \%$ of study families participated in the age 5 interview.

At the time of recruitment into the evaluation, 25\% of mothers were married and an additional $6 \%$ unmarried and living with a partner. Fifty-eight percent of mothers were unmarried and not living with a partner and about $11 \%$ separated, widowed, or divorced (St.Pierre et al., 1997). Because the study began after the intervention started and because some participating children had not been born yet, complete interview data are not available at baseline. A limited range of information involving family demographics is available, and this is presented in Table 1, which describes our working sample at the first interview. This sample of roughly 2,000 children and their mothers represents a subset of the original and complete sample. We eliminated several groups, including a very small number $(3 \%)$ of children who were no longer living with their mothers by the time of the first interview and those for whom key child outcome data were not collected. In the analyses described below, the sample sizes vary somewhat across analyses and outcome measures. At some of the latter waves, for example, some study children had aged out of the age range for which a given measure was appropriate.

It is important to note that $95 \%$ of sample families contribute to analyses of at least one outcome in three or four waves of data collection. The average was 3.55 
Table 1

Description of Sample at First Interview

\begin{tabular}{|c|c|c|c|c|c|c|}
\hline & \multicolumn{2}{|c|}{ Black } & \multicolumn{2}{|c|}{ Latino } & \multicolumn{2}{|c|}{ White } \\
\hline & $M$ or $\%$ & $S D$ & $M$ or $\%$ & $S D$ & $M$ or $\%$ & $S D$ \\
\hline \multicolumn{7}{|l|}{ Demographics } \\
\hline Child age (months) & 24.9 & 1 & 25.28 & 1.18 & 24.91 & 0.96 \\
\hline Maternal age (years) & 24.77 & 5.89 & 27.12 & 6.1 & 26.31 & 5.81 \\
\hline Children in household & 2.6 & 1.09 & 2.7 & 1.08 & 2.29 & 1.02 \\
\hline Adults in household & 1.81 & 0.95 & 2.15 & 0.98 & 1.97 & 0.74 \\
\hline \multicolumn{7}{|l|}{ Socioeconomic status } \\
\hline Mother employed & $26 \%$ & - & $27 \%$ & - & $40 \%$ & - \\
\hline Family income $(\$ 1,000)$ & 9.2 & 9 & 10.03 & 6.95 & 12.06 & 8.83 \\
\hline \multicolumn{7}{|l|}{ Parental socialization } \\
\hline Sees father & $75 \%$ & - & $82 \%$ & - & $80 \%$ & - \\
\hline Feels close to mother & $91 \%$ & - & $85 \%$ & - & $87 \%$ & - \\
\hline Spends time with mother & $2.98 \%$ & 1.22 & 3.16 & 1.15 & 2.95 & 1.18 \\
\hline Mother expects child to drop out & $16 \%$ & - & $32 \%$ & - & $13 \%$ & - \\
\hline \multicolumn{7}{|l|}{ Mother's mental health } \\
\hline Depressive symptoms & 45.27 & 12.44 & 44.39 & 12.7 & 43.05 & 13.81 \\
\hline Mastery & 20.76 & 3.53 & 19.66 & 3.4 & 20.45 & 4.52 \\
\hline \multicolumn{7}{|l|}{ Out-of-home contexts } \\
\hline Neighborhood safety & 2.29 & 1.15 & 2.73 & 1.12 & 3.04 & 1.26 \\
\hline \multicolumn{7}{|l|}{ Day care arrangements } \\
\hline Center based & $30 \%$ & - & $16 \%$ & - & $24 \%$ & - \\
\hline Relative & $23 \%$ & - & $22 \%$ & - & $22 \%$ & - \\
\hline Nonrelative & $7 \%$ & - & $9 \%$ & - & $12 \%$ & - \\
\hline Mother is primary caregiver & $40 \%$ & - & $53 \%$ & - & $42 \%$ & - \\
\hline
\end{tabular}

waves. Among individuals lacking a single wave of data, $78 \%$ of the cases were missing the age 2 data as discussed above. Our analyses below rely on the properties of fixed effects estimation to ensure that our results are not distorted by selective attrition. In particular, by conditioning on all time-invariant characteristics, fixed effect extends the reach of the missingat-random assumption to include all time-invariant characteristics. As a result, it is more likely that the data are missing at random and the missing data mechanism ignorable. The increased robustness of fixed effects estimation to alternative forms of attrition may represent another reason why the random and fixed effects estimation differ (Foster \& Bickman, 1996; Little \& Rubin, 2002; Verbeek \& Nijman, 1992). (Multiple imputation procedures using observed measures of time-invariant characteristics would cover a more limited range of missing data mechanisms, but one might include other time-varying covariates in an imputation scheme. In the case at hand, the most likely candidates would be the other outcome measures; for example, we might include the change in the Child Behavior Checklist (CBCL) scores to impute missing Peabody Picture Vocabu- lary Test (PPVT) data. The effect of doing so is likely small because (1) the correlation across measures is small and (2) most nonresponse at a given wave was unit nonresponse.)

The interviews covered a range of topics. Mothers reported on their own economic self-sufficiency (employment, public assistance, and preparation for employment) as well as their own feelings, behaviors, and attitudes that might affect their child's development. The latter included their psychological wellbeing, attitudes toward parenting, the characteristics of their home as a context for development, and parent-child interaction.

A variety of age-appropriate measures was included concerning the child's growth and development. These involved parental reports of the child's behavior and well-being as well as direct, age-appropriate assessments by trained assessors. Our analyses focus on three measures of child development. We selected these measures based on widespread use in research on child development as well as on the fact that they were collected in multiple interviews, thus permitting the use of the fixed effects regression techniques. 
The first of these outcomes is the CBCL (Achenbach, 1978; Achenbach \& Edelbrock, 1979; Edelbrock \& Achenbach, 1980,1984), a parent report of more than 100 emotional and behavioral problems. The measure generates a total score as well as two broadband scores representing internalizing and externalizing problems. The study used two versions of the CBCL: those for ages $2-3$ and for ages 4-18. Complementing the CBCL is a second measure, the Adaptive Social Behavior Inventory (ASBI) (Greenfield, Iruka, \& Munis, 2004; Greenfield, Wasserstein, Gold, \& Jorden, 1997). Developed for the Infant Health and Development Project, the ASBI captures adaptive or prosocial behavior for high-risk 3-year-olds. The measure generates a total score and three subscales-express, comply, and disrupt. This measure was administered when the children were at ages 3 and 4 (a shortened version was administered at age 2 as well). The third child measure is the PPVT (Dunn \& Brooks, 1960; Gage \& Naumann, 1965; Norris, Hottel, \& Brooks, 1960; Rice \& Brown, 1967), a measure of verbal ability and literacy-related skills. This measure was collected at ages 3,4, and 5. The test consists of 175 vocabulary items that children match to the appropriate picture.

\section{Living Arrangements}

At each interview, respondents also completed a household roster and answered a question about the presence or absence of the child's biological father in the household. Using this information, we classified families into one of four types at each interview: mother only (38\% at the first interview), mother and biological father $(33 \%)$, blended (i.e., mother with male partner who is not the child's biological father [15\%]), and multigenerational (i.e., single mother living with child's grandmother [14\%]). Race-/ethnicity-specific breakdowns for these groups are provided in the Results. Ideally, we would have differentiated these groups further by separating biological father families and blended families into married and unmarried households, following Brown (2004). Given the sample sizes, however, doing so was not possible. However, nearly $90 \%$ of mothers living with the child's biological father reported that the couple was married. To preserve sample size, we retain the small number of unmarried biological parent families in this group. Seventy-three percent of the mothers in the blended families reported that she and the man were married. Thus, this group combines married and unmarried blended families (recall that previous studies have shown minimal differences in child well-being between the two [Brown, 2004]).
The analyses also control for two other dimensions of household composition-the number of children and adults in the household and the maternal and child age.

\section{Mediators}

The interview data also provide information on a variety of family characteristics that can be used to explain the potential linkages between living arrangements and child development, following the theoretical framework laid out above: economic conditions, including family income and maternal employment; parental socialization, including maternal well-being, parental involvement, and mothers' educational aspirations; and out-of-home environments, including measures of neighborhood quality and children's care arrangements.

Socioeconomic conditions are assessed with two variables: whether the mothers were working at the time of the interview (coded " 1 " if yes) and family income (rescaled into thousands of dollars). The parental socialization measures include three items assessing parental involvement: whether the child sees his or her father (dummy coded as yes/no), whether the mother feels "very close" to her child (as reported by the mother; dummy code as yes/no), and how much time the child spends with the mother each day (coded in six categories ranging from none to more than 2 hours), as well as a single-item measure of mothers' educational expectations for her child (coded " 1 " if the mother does not expect the child to complete high school).

Maternal mental health is assessed with two measures. Maternal depression is measured using the 20-item Center for Epidemiological Studies Depression (CES-D) scale (Orme, Reis, \& Herz, 1986; Roberts \& Vernon, 1983); maternal mastery is measured using the 7-item Pearlin and Schooler Mastery Scale (Pearlin \& Schooler, 1978). Higher levels on the CES-D scale indicate a higher prevalence of depressive symptoms, whereas higher scores on the Mastery Scale indicate a greater sense that one's life is under one's own control rather than determined by fate. A score of 16 or above on the CES-D scale is commonly used as an indicator of clinical depression; $42 \%$ of mothers in both the CCDP and the control group had average scores of 16 or higher (St.Pierre et al., 1997).

Out-of-home environments are assessed with mothers' ratings of the quality of their neighborhood as a place to raise children on a scale from 1 (poor) to 5 (excellent) and also their reports of the usual source of child care while mothers are working, looking for work, or are in school. We used that information to 
classify children in one of four primary care categories: the mother herself (the reference group), centerbased child care, other relative, or other nonrelative.

\section{Statistical Model}

As discussed above, a central issue surrounding the association between living arrangements and child outcomes involves separating the effect of living arrangements from that of confounding factors. Our strategy involves fixed effects estimation. This technique is commonly used in economics (Wooldridge, 2002) and is increasingly used in developmental science. This method has been used to examine a variety of topics, including teenage childbearing and its effects on child outcomes (Hoffman, 2007; Hoffman, Foster, \& Furstenberg, 1993), maternal employment, and child well-being (Dunifon \& Kowaleski-Jones, 2002) as well as studies of schoolage children's living arrangements (Dunifon \& Kowaleski-Jones, 2002).

Fixed effects estimation involves comparing changes in a relevant outcome across groups of children experiencing changes in the explanatory variable of interest (living arrangements, in this case). By comparing the same child at different points in time, the model holds constant or adjusts for all child and family characteristics that are stable over time. As a result, all time-invariant confounding factors are controlled for, whether they are measured or not.

We can represent this model with the following equation:

$$
Y_{i, t}=\beta X_{i, t}+\mu_{i}+\varepsilon_{i, t},
$$

where $\varepsilon_{i, t}$ indicates observation from time period $t$ for child $i . Y$ is the outcome of interest, and $X$ represents the set or the vector of explanatory variables. $\beta$ represents the effect of the latter on the former. The distinguishing feature of the model is $\mu_{i}$. It represents child and family characteristics that are constant over time. Time-varying unexplained variation is represented by $\varepsilon$. This model makes no assumptions about the distribution of these child-specific terms. They can be normally distributed (or not) and can be correlated with key explanatory variables, such as living arrangements.

Several key features distinguish this model. First and foremost, Equation 1 still specifies a "levels" model—it models child outcomes at a point in time as a function of family living arrangements at that time. The longitudinal nature of the data matters to the extent that it provides repeated measures of levels of outcomes and living arrangements. Second, the fixed effects model cannot be used to examine the effect of characteristics that are stable over time (such as race/ethnicity). In the estimation stage, characteristics that do not change over time drop out of the model. As a result, we can estimate the effect of living arrangements only because living arrangements change over time.

Finally, note that the model does not control for all potentially confounding factors that do change over time. As a result, the effects of living arrangements are potentially confounded with changes in the factors not included in the model. Our analyses do, however, include key time-varying potential predictors of children's well-being, such as maternal depression.

An alternative to the fixed effects model is the standard random effects (or random intercept) model. In particular, that model represents a more restrictive form of the model described above: The random effects model assumes that the child-specific terms are normally distributed and uncorrelated with the other variables in the model. If these assumptions are true, the resulting parameter estimates will be more precisely estimated (or efficient). However, if they are not, then the estimates will be incorrect (or biased), even in large samples. A key question, therefore, is whether the fixed and random effects estimates differ statistically. One can test the null hypothesis that the estimates are the same using the Hausman test. If one rejects that hypothesis, one should rely on the fixed effects estimates.

\section{Results}

\section{Sample Description}

Table 1 presents the characteristics of the sample. Descriptive data are provided separately for the three racial and ethnic groups. In addition, consistent with our empirical model, the unit of observation for the table is the wave-individuals contributing multiple waves of data are included in the tables multiple times (tables calculated at the individual level resemble those presented here). The variation in sample size across rows reflects low levels of items missing. The standard errors for the parameter estimates are corrected to allow for the interdependence among observations for the same individual.

For many of the child and family characteristics, the three racial and ethnic groups are quite similar. For example, average age of the women was similar as were characteristics of their mental health. All three groups have an average total income less than $\$ 15,000 /$ year.

Nonetheless, although smaller than what one would see in nationally representative data for the groups, 
significant differences separate the three groups. Even in this low-income sample, average income for Whites is $30 \%$ greater than that for the other two groups. At least to some extent, this difference reflects differences in employment. Thirty-four percent of the Black mothers and $32 \%$ of Latina mothers were working compared to $46 \%$ of the White mothers.

Other striking differences include perceived neighborhood safety. Both Latina and Black mothers judged their neighborhood to be less safe than did White mothers. Child-care arrangements also differed across the groups. Latina mothers (51\%) were less dependent on out-of-home settings such as child-care centers and relatives than were White $(60 \%)$ and Black (58\%) mothers.

Perhaps most striking were the differences across groups in expectations for their children's long-term education. In this regard, Latina mothers differed especially from the other two groups; they were twice as likely to expect their child not to complete high school as were Black and White mothers $(12 \%$ and $10 \%$, respectively).

\section{Living Arrangements}

Table 2 presents the distribution of living arrangements across waves and by race/ethnicity. Mother only was the dominant family structure among Black families (54\%), whereas biological father present was most prevalent for Latino and White families (51\% and $44 \%$, respectively). Multigenerational households were more common among Black families $(15 \%)$ than among Latinos $(9 \%)$ or Whites $(6 \%)$. In this sample, blended families were more common among Whites ( $24 \%$ ) than among Blacks $(17 \%)$ or Latinos $(11 \%)$. Thus, the variation in living arrangements across the three race/ethnic groups in this low-income sample correspond to those apparent in nationally representative data (e.g., Wherry \& Finegold, 2004).

The panels of Table 2 reveal that the distribution of families across types was fairly stable over time. One can see, however, that some categories suffered net losses of families over time. For example, the percentage of multigenerational families fell substantially across waves (from $21 \%$ to $12 \%$ ). For both Whites and Latinos, a notable change involved the increase in the percentage of blended families. Although lower than for Whites, the percentage of such families among Latinos more than doubled, from 5\% to $13 \%$. This relative stability, however, hides considerable dynamics at the family level. Between the first and second waves, $29 \%$ of the overall sample changed categories. Among the more common patterns were grand-
Table 2

Living Arrangements Over Time and by Race/Ethnicity

\begin{tabular}{lrrrr}
\hline & Wave & Wave & Wave & Wave \\
& \multicolumn{1}{c}{$\begin{array}{r}\text { 1 } \\
\text { Black }\end{array}$} & \multicolumn{1}{c}{3} & \multicolumn{1}{c}{4} \\
\hline Total number & 848 & 1,181 & 1,186 & 1,265 \\
Biological father household (\%) & 14 & 14 & 12 & 14 \\
Blended (\%) & 15 & 16 & 20 & 18 \\
Multigenerational (\%) & 21 & 16 & 13 & 12 \\
Mother only (\%) & 50 & 54 & 54 & 56 \\
Latino & & & & \\
Total number & 572 & 783 & 797 & 831 \\
Biological father household (\%) & 55 & 51 & 50 & 50 \\
Blended (\%) & 5 & 11 & 12 & 13 \\
Multigenerational (\%) & 12 & 10 & 8 & 6 \\
Mother only (\%) & 27 & 27 & 30 & 31 \\
White & & & & \\
Total number & 606 & 775 & 745 & 808 \\
Biological father household (\%) & 53 & 45 & 42 & 39 \\
Blended (\%) & 17 & 23 & 26 & 29 \\
Multigenerational (\%) & 8 & 6 & 5 & 5 \\
Mother only (\%) & 23 & 26 & 26 & 26 \\
\hline
\end{tabular}

mothers leaving the homes and being "replaced" by other men.

\section{Child Development Outcomes}

Table 3 summarizes the mean scores of the four child outcome variables across the four waves for each racial/ethnic group. In general, the scores improved for all four measures over time (in the case of the two CBCL measures, improvement corresponds to reductions in the score). These trends reflect two forces. First, the scores on the given measure may rise or fall over time for all children due to development. In addition, the children in this study may improve over time relative to their peers. Because the $\mathrm{CBCL}$ is age normed, improvements in that measure represent the second of these only. For that reason, the improvements in the CBCL scores are somewhat smaller (in percentage terms) than for the other two measures. These patterns hold for all racial and ethnic groups.

\section{Living Arrangements and Children's Internalizing Problems}

Table 4 presents the results of our first set of multivariate regression analyses. For each outcome and racial/ethnic group, we present two sets of estimates. The first (Model 1) includes only the three living arrangement dummy variables (the reference group is mother-only households) and the child's age 
Table 3

Outcomes Over Time and by Race/Ethnicity

\begin{tabular}{|c|c|c|c|c|c|c|c|c|}
\hline & \multicolumn{2}{|c|}{ Wave 1} & \multicolumn{2}{|c|}{ Wave 2} & \multicolumn{2}{|c|}{ Wave 3} & \multicolumn{2}{|c|}{ Wave 4} \\
\hline & $M$ & $S D$ & $M$ & $S D$ & $M$ & $S D$ & $M$ & $S D$ \\
\hline \multicolumn{9}{|l|}{ Black } \\
\hline Externalizing behavior & 57.19 & 9.02 & 54.21 & 10.80 & 53.74 & 10.54 & 50.83 & 11.51 \\
\hline Internalizing behavior & 57.24 & 10.05 & 56.39 & 11.36 & 48.82 & 10.10 & 46.41 & 10.56 \\
\hline Prosocial behavior & 20.36 & 3.51 & 32.34 & 6.22 & 33.43 & 5.96 & 32.60 & 8.02 \\
\hline Receptive vocabulary & 24.90 & 1 & 38.10 & 2.75 & 49.87 & 2.20 & 63.49 & 3.19 \\
\hline \multicolumn{9}{|l|}{ Latino } \\
\hline Externalizing behavior & 54.96 & 9.48 & 53.14 & 10.16 & 52.71 & 10.64 & 50.90 & 11.57 \\
\hline Internalizing behavior & 55.70 & 11.08 & 55.43 & 11.32 & 49.50 & 10.04 & 48.91 & 10.87 \\
\hline Prosocial behavior & 21.49 & 3.94 & 33.76 & 6.43 & 33.96 & 6.41 & 41 & - \\
\hline Receptive vocabulary & 25.27 & 1.17 & 37.94 & 2.51 & 49.57 & 1.80 & 62.72 & 2.25 \\
\hline \multicolumn{9}{|l|}{ White } \\
\hline Externalizing behavior & 54.89 & 9.19 & 54.06 & 10 & 55.20 & 10.58 & 52.81 & 11.55 \\
\hline Internalizing behavior & 53.70 & 9.38 & 54.84 & 10.25 & 48.89 & 9.69 & 48.24 & 10.24 \\
\hline Prosocial behavior & 21.96 & 3.85 & 34.67 & 5.92 & 35.63 & 6.19 & 30 & 13.89 \\
\hline Receptive vocabulary & 24.91 & 0.96 & 38.17 & 2.58 & 49.96 & 2.01 & 63.62 & 3.44 \\
\hline
\end{tabular}

as regressors. These estimates reveal the total effect of family structure.

For the second set of analyses (Model 2), a wide array of covariates are added-these were included to better distinguish the effect of living arrangements from other family and child characteristics that might covary with them as well as those that could mediate any linkages between living arrangements and child well-being. The effects of these other variables on child outcomes are also of interest. Taken together, comparisons of Models 1 and 2 allow one to assess whether and how the effect of living arrangements on child outcomes is mediated.

We began by considering whether we can reject the assumptions on which random effects estimation rest. The null hypothesis that the child-specific effects were normally distributed and uncorrelated with the other variables in the model was rejected in every case for Latino and Black families. These results suggest that conventional analyses based on ordinary least squares regression may be misleading-living arrangements apparently are correlated with unobserved factors that influence child outcomes. For Whites, we were unable to reject the null hypothesis that the assumptions of random effects estimation fit the data. However, to maintain consistency across the three groups, we still report the fixed effect estimates for Whites (the random effect estimates are available upon request). This finding also highlights the importance of running separate models by racial and ethnic groups.
The top panel of each column reports the significance of the three living arrangements dummy variables-these correspond to the difference between each group and the mother-only families. The lower panel of the table also reports joint significance of the three dummy variables; this corresponds to a test of the overall significance of variation across the living arrangement categories (this test involved a likelihood ratio test with three degrees of freedom).

Only for Black families is the variation across living arrangements significant $(p=.05)$ and only prior to the addition of any covariates. All the effects are very small in practical terms, corresponding to $0.5-1.5$ point differences in the baseline score (an effect size smaller than 0.05). More importantly, the effects of other predictors dwarf that of living arrangements; particularly powerful are maternal expectations for the child completing high school. This effect is strong and significant for Black mothers. For two of the three groups (Blacks and Whites), mothers' depressive symptoms are also an important predictor of children's internalizing problems.

\section{Living Arrangements and Children's Externalizing Problems}

Table 5 shows that the effect of living arrangements on externalizing problems was significant among Black children, even after covariates are included $(p=.04)$. Black children living in a blended family had more externalizing problems than children living 
Table 4

Living Arrangements and Children's Internalizing Behavior Problems by Race

\begin{tabular}{|c|c|c|c|c|c|c|}
\hline & \multicolumn{2}{|c|}{ Black } & \multicolumn{2}{|c|}{ Latino } & \multicolumn{2}{|c|}{ White } \\
\hline & Model 1 & Model 2 & Model 1 & Model 2 & Model 1 & Model 2 \\
\hline \multicolumn{7}{|l|}{ Living arrangements, $\beta(S E)$} \\
\hline Biological father & $-0.36(0.65)$ & $-0.09(0.85)$ & $-1.24(0.71)$ & $-0.82(0.97)$ & $-0.61(0.71)$ & $-0.87(0.96)$ \\
\hline Blended & 0.74 & $1.51(0.87)$ & $-0.54(0.79)$ & $-0.04(1.12)$ & $-0.52(0.66)$ & $-1.08(0.92)$ \\
\hline Multigenerational & $1.46(0.58)$ & $0.45(0.87)$ & $-1.48(0.94)$ & $-0.46(1.44)$ & $-1.29(1.01)$ & $-2.39(1.53)$ \\
\hline \multicolumn{7}{|l|}{ Other demographics, $\beta$ (SE) } \\
\hline Child age & $-0.32(0.01)^{* *}$ & $-0.29(0.02)$ & $-0.21(0.01)^{* *}$ & $-0.22(0.03)^{* *}$ & $-0.19(0.01)^{* *}$ & $-0.22(0.03)^{* *}$ \\
\hline Maternal age & & $-0.30(0.25)$ & & $-0.06(0.30)$ & & $0.27(0.32)$ \\
\hline Children in household & & $0.25(0.35)$ & & $0.90(0.52)$ & & $0.50(0.49)$ \\
\hline Adults in household & & $0.30(0.37)$ & & $-0.25(0.40)$ & & $0.14(0.47)$ \\
\hline \multicolumn{7}{|l|}{ Socioeconomic status, $\beta$ (SE) } \\
\hline Mother employed & & $-0.64(0.51)$ & & $-0.18(0.65)$ & & $0.62(0.56)$ \\
\hline Family income $(\$ 1,000)$ & & $0.05(0.03)$ & & $0.05(0.04)$ & & $0.06(0.03)^{*}$ \\
\hline \multicolumn{7}{|l|}{ Parental socialization, $\beta(S E)$} \\
\hline Sees father & & $-0.65(0.56)$ & & $-0.34(0.84)$ & & $0.27(0.88)$ \\
\hline Feels close to mother & & $0.73(0.64)$ & & $-1.06(0.58)$ & & $-0.47(0.71)$ \\
\hline Spends time with mother & & $-0.48(0.16)^{* *}$ & & $-0.41(0.19)^{*}$ & & $-0.20(0.21)$ \\
\hline Mother expects child to drop out & & $2.44(0.61)^{* *}$ & & $1(0.55)$ & & $1.17(0.91)$ \\
\hline \multicolumn{7}{|l|}{ Mother's mental health, $\beta$ (SE) } \\
\hline Depressive symptoms & & $1.53(0.25)^{* *}$ & & $0.39(0.29)$ & & $1.50(0.28)^{* *}$ \\
\hline Mastery & & $-0.02(0.26)$ & & $-0.70(0.35)^{*}$ & & $-0.36(0.31)$ \\
\hline \multicolumn{7}{|l|}{ Out-of-home contexts, $\beta$ (SE) } \\
\hline Neighborhood safety & & $-0.20(0.20)$ & & $0.26(0.25)$ & & $0.09(0.22)$ \\
\hline \multicolumn{7}{|l|}{ Day care arrangements, $\beta(S E)$} \\
\hline Center-based child care & & $0.22(0.49)$ & & $-0.50(0.64)$ & & $-0.74(0.64)$ \\
\hline Relative child care & & $1.11(0.58)$ & & $-1.10(0.69)$ & & $-0.58(0.68)$ \\
\hline Nonrelative child care & & $1.35(0.92)$ & & $0.11(1)$ & & $-1.92(0.82)^{*}$ \\
\hline$R^{2}$ & 0.29 & 0.32 & 0.14 & -0.15 & 0.13 & 0.16 \\
\hline $\begin{array}{l}\text { Joint significance of living } \\
\text { arrangements }\end{array}$ & 0.05 & 0.28 & 0.22 & 0.83 & 0.57 & 0.41 \\
\hline Hausaman test & 0.01 & & 0.05 & & 0.06 & \\
\hline Number of waves & 4,388 & 3,337 & 2,930 & 2,352 & 2,878 & 2,296 \\
\hline Number of individuals & 1,265 & 1,171 & 831 & 810 & 808 & 761 \\
\hline
\end{tabular}

$* p<.05 . * * p .01$.

with only their mother. Although the presence of a grandmother is associated with greater externalizing problems (Model 1), the effect vanishes once we account for the other covariates. The other significant living arrangement coefficient indicated lower levels of externalizing problems for White children living with their biological fathers versus only their mothers. This effect was modest in practical terms, corresponding to an effect size less than 0.15 and was no longer statistically significant once the additional controls were added.

As in the model for internalizing problems, child's age was negatively related to externalizing problems, indicating that as children grew older, externalizing problems diminished. Again, we see that maternal educational expectations and depressive symptoms strongly predict child behavior problems for White and Black children.

\section{Living Arrangements and Children's Prosocial Behavior}

The relationship between living arrangements and prosocial behavior is especially weak (Table 6). The only coefficient that is statistically significant involves the coefficient on multigenerational households for Latinos. When covariates are added, the effect is cut in half and is no longer statistically significant.

\section{Living Arrangements and Children's Verbal-and Literacy-Related Skills}

For none of the three groups was the overall variation in PPVT scores across living arrangements significant, although for Black and Latino children, some of the group-wise comparisons were significant 
Table 5

Living Arrangements and Children's Externalizing Behavior Problems by Race

\begin{tabular}{|c|c|c|c|c|c|c|}
\hline & \multicolumn{2}{|c|}{ Black } & \multicolumn{2}{|c|}{ Latino } & \multicolumn{2}{|c|}{ White } \\
\hline & Model 1 & Model 2 & Model 1 & Model 2 & Model 1 & Model 2 \\
\hline \multicolumn{7}{|l|}{ Living arrangements, $\beta$ (SE) } \\
\hline Biological father & $-0.78(0.63)$ & $-0.67(0.83)$ & $-0.44(0.67)$ & $0.02(0.88)$ & $-1.60(0.68)^{*}$ & $-1.72(0.91)$ \\
\hline Blended & $1.38(0.53)^{* *}$ & $1.78(0.85)^{*}$ & $-0.02(0.73)$ & $-1.15(1.03)$ & $-1.07(0.63)$ & $-0.79(0.87)$ \\
\hline Multigenerational & $1.75(0.56)^{* *}$ & $0.77(0.85)$ & $-1.54(0.88)$ & $-0.98(1.32)$ & $-1.78(0.97)$ & $-1.37(1.44)$ \\
\hline \multicolumn{7}{|l|}{ Other demographics, $\beta$ (SE) } \\
\hline Child age & $-0.15(0.01)^{* *}$ & $-0.11(0.02)^{* *}$ & $-0.10(0.010)^{* *}$ & $-0.06(0.03)^{*}$ & $-0.05(0.01)^{* *}$ & $-0.06(0.03)$ \\
\hline Maternal age & & $-0.33(0.24)$ & & $-0.10(0.28)$ & & $0.16(0.31)$ \\
\hline Children in household & & $0.53(0.34)$ & & $0.08(0.48)$ & & $0.17(0.46)$ \\
\hline Adults in household & & $0.43(0.36)$ & & $0.21(0.37)$ & & $0.15(0.45)$ \\
\hline \multicolumn{7}{|l|}{ Socioeconomic status, $\beta$ (SE) } \\
\hline Mother employed & & $-0.85(0.50)$ & & $-1.54(0.60)^{* *}$ & & $0.19(0.53)$ \\
\hline Family income $(\$ 1,000)$ & & $0.01(0.03)$ & & $0.01(0.03)$ & & $0 \quad(0.03)$ \\
\hline \multicolumn{7}{|l|}{ Parental socialization, $\beta(S E)$} \\
\hline Sees father & & $-0.39(0.55)$ & & $-1.45(0.77)$ & & $-0.09(0.83)$ \\
\hline Feels close to mother & & $-0.35(0.62)$ & & $-0.80(0.53)$ & & $-0.90(0.67)$ \\
\hline Spends time with mother & & $-0.45(0.16)^{* *}$ & & $0.03(0.17)$ & & $-0.14(0.20)$ \\
\hline Mother expects child to drop out & & $2.05(0.59)^{* *}$ & & $1.27(0.51)^{*}$ & & $2.14(0.86)^{*}$ \\
\hline \multicolumn{7}{|l|}{ Mother's mental health, $\beta$ (SE) } \\
\hline Depressive symptoms & & $1.48(0.24)^{* *}$ & & $0.41(0.27)$ & & $1.59(0.27)^{* *}$ \\
\hline Mastery & & $0.19(0.25)$ & & $-0.20(0.32)$ & & $-0.04(0.30)$ \\
\hline \multicolumn{7}{|l|}{ Out-of-home contexts, $\beta$ (SE) } \\
\hline Neighborhood safety & & $-0.30(0.19)$ & & $-0.12(0.22)$ & & $-0.04(0.21)$ \\
\hline \multicolumn{7}{|l|}{ Day care arrangements, $\beta$ (SE) } \\
\hline Center-based child care & & $-0.11(0.48)$ & & $0.01(0.58)$ & & $-0.70(0.61)$ \\
\hline Relative child care & & $1.73(0.56)^{* *}$ & & $-0.86(0.63)$ & & $-0.16(0.64)$ \\
\hline Nonrelative child care & & $1.29(0.90)$ & & $1.17(0.91)$ & & $-0.87(0.78)$ \\
\hline$R^{2}$ & 0.09 & 0.13 & 0.04 & 0.05 & 0.01 & 0.05 \\
\hline Joint significance of living arrangements & 0 & 0.04 & 0.30 & 0.60 & 0.06 & 0.29 \\
\hline Hausaman test & 0.04 & & 0 & & 0.17 & \\
\hline Number of waves & 4,388 & 3,337 & 2,930 & 2,352 & 2,878 & 2,296 \\
\hline Number of individuals & 1,265 & 1,171 & 831 & 810 & 808 & 761 \\
\hline
\end{tabular}

$* p<.05 .{ }^{* *} p<.01$.

(Table 7). In particular, Black children living with their biological father showed higher PPVT scores than their counterparts in mother-only households. This effect remained statistically significant once we included the other covariates. Second, Latino children living in a blended family showed higher PPVT scores than their counterparts in mother-only households. This effect was statistically significant whether the other covariates are included or not. In either case, the effect was modest in practical terms, corresponding to an effect size less than 0.20 .

Here, we also see the effect of maternal depressive symptoms. Again, for Black and White (but not for Latino) children, those whose mothers reported higher levels of depressive symptoms showed lower PPVT scores.
In supplemental analyses, we analyzed other outcome measures, including the Kaufman Assessment Battery for Children (Kaufman et al., 2005; Lichtenberger, Kaufman, \& Bracken, 2000, 2004). The results of those analyses are consistent with those presented here and are available from the first author.

\section{Discussion}

In general, we find little evidence that living arrangements predict child well-being in a very low-income sample, regardless of the child's race or ethnicity. Of course, it is impossible to prove the null hypothesis that family structure has no effect. Nonetheless, for none of our four outcomes was a joint test of all the 
Table 6

Living Arrangements and Children's Prosocial Behavior by Race

\begin{tabular}{|c|c|c|c|c|c|c|}
\hline & \multicolumn{2}{|c|}{ Black } & \multicolumn{2}{|c|}{ Latino } & \multicolumn{2}{|c|}{ White } \\
\hline & Model 1 & Model 2 & Model 1 & Model 2 & Model 1 & Model 2 \\
\hline \multicolumn{7}{|l|}{ Living arrangements, $\beta$ (SE) } \\
\hline Biological father & $0.57(0.56)$ & $0.30(0.73)$ & $0.51(0.68)$ & $0.25(0.89)$ & $-0.41(0.61)$ & $-1.40(0.82)$ \\
\hline Blended & $-0.49(0.48)$ & $-0.17(0.74)$ & $1.35(0.78)$ & $1.01(1.08)$ & $-0.43(0.59)$ & $-0.22(0.81)$ \\
\hline Multigenerational & $-0.75(0.51)$ & $-0.60(0.78)$ & $1.81(0.89)^{*}$ & $0.93(1.35)$ & $-1.31(0.89)$ & $-1.45(1.39)$ \\
\hline \multicolumn{7}{|l|}{ Other demographics, $\beta$ (SE) } \\
\hline Child age & $0.49(0.01)^{* *}$ & $0.48(0.02)^{* *}$ & $0.47(0.01)^{* *}$ & $0.49(0.03)^{* *}$ & $0.52(0.01)^{* *}$ & $0.51(0.03)^{* *}$ \\
\hline Maternal age & & $0.07(0.23)$ & & $-0.39(0.30)$ & & $0.06(0.31)$ \\
\hline Children in household & & $0.05(0.30)$ & & $-0.04(0.49)$ & & $0.06(0.43)$ \\
\hline Adults in household & & $-0.19(0.32)$ & & $-0.44(0.37)$ & & $0.14(0.40)$ \\
\hline \multicolumn{7}{|l|}{ Socioeconomic status, $\beta$ (SE) } \\
\hline Mother employed & & $-0.15(0.44)$ & & $0.16(0.60)$ & & $1.26(0.48)^{* *}$ \\
\hline Family income $(\$ 1,000)$ & & $-0.01(0.03)$ & & $0.08(0.03)^{*}$ & & $0.03(0.03)$ \\
\hline \multicolumn{7}{|l|}{ Parental socialization, $\beta$ (SE) } \\
\hline Sees father & & $0.20(0.50)$ & & $-1.22(0.79)$ & & $0.89(0.81)$ \\
\hline Feels close to mother & & $2.66(0.55)^{* *}$ & & $0.78(0.56)$ & & $-0.59(0.61)$ \\
\hline Spends time with mother & & $0.03(0.14)$ & & $0.34(0.17)$ & & $0.35(0.18)$ \\
\hline Mother expects child to drop out & & $0.24(0.52)$ & & $-0.94(0.50)$ & & $0.11(0.73)$ \\
\hline \multicolumn{7}{|l|}{ Mother's mental health, $\beta(S E)$} \\
\hline Depressive symptoms & & $-0.32(0.21)$ & & $-0.31(0.26)$ & & $-0.09(0.23)$ \\
\hline Mastery & & $-0.10(0.23)$ & & $0.49(0.31)$ & & $0.08(0.26)$ \\
\hline \multicolumn{7}{|l|}{ Out-of-home contexts, $\beta$ (SE) } \\
\hline Neighborhood safety & & $0.26(0.17)$ & & $0.49(0.23)^{*}$ & & $0.02(0.16)$ \\
\hline \multicolumn{7}{|l|}{ Day care arrangements, $\beta$ (SE) } \\
\hline Center-based child care & & $0.32(0.44)$ & & $0.09(0.62)$ & & $-0.05(0.56)$ \\
\hline Relative child care & & $-0.23(0.49)$ & & $-0.30(0.63)$ & & $-0.39(0.57)$ \\
\hline Nonrelative child care & & $-0.81(0.76)$ & & $-0.69(0.91)$ & & $-0.61(0.66)$ \\
\hline$R^{2}$ & 0.56 & 0.56 & 0.48 & 0.50 & 0.61 & 0.60 \\
\hline $\begin{array}{l}\text { Joint significance of living } \\
\text { arrangements }\end{array}$ & 0.17 & 0.77 & 0.17 & 0.78 & 0.52 & 0.29 \\
\hline Hausaman test & 0 & & 0 & & 0.14 & \\
\hline Number of waves & 3,138 & 2,449 & 2,102 & 1,770 & 2,081 & 1,707 \\
\hline Number of individuals & 1,261 & 1,128 & 831 & 800 & 806 & 739 \\
\hline
\end{tabular}

${ }^{*} p<.05 .{ }^{*} p<.01$.

living arrangement groups significant. The lack of statistical significance is not driven by large standard errors. The fixed effects estimates can be distinguished statistically from the random effect estimates; furthermore, the former are small in practical terms.

An important contribution of the article is the use of fixed effects estimation. For two of the three racial/ ethnic groups, we can reject the null hypothesis that the time-invariant unobserved factors, $\mu_{i}$, are independent of living arrangements for all outcomes. These findings suggest that the results of a standard growth curve analysis (or random intercept model) would be misleading. Somewhat surprisingly, for Whites, we cannot reject the random effects model for three of the four outcomes. One explanation for this finding could be the smaller sample size for Whites, but that subgroup is comparable in size to the Latino subgroup. Another explanation is that the sorting of women into different family structures differs by race and ethnicity. If true, that finding strongly supports estimating these models separately for the three groups.

Why do we find so few of the expected relationships? One explanation could be poor measurement of the outcomes. Such imprecision would not produce biased point estimates but would inflate standard errors. In these analyses, the point estimates are quite small in practical terms. Furthermore, the measures used here are among the best developmental science has to offer and have been used in many studies. That 
Table 7

Living Arrangements and Children's Vocabulary by Race

\begin{tabular}{|c|c|c|c|c|c|c|}
\hline & \multicolumn{2}{|c|}{ Black } & \multicolumn{2}{|c|}{ Latino } & \multicolumn{2}{|c|}{ White } \\
\hline & Model 1 & Model 2 & Model 1 & Model 2 & Model 1 & Model 2 \\
\hline \multicolumn{7}{|l|}{ Living arrangements, $\beta$ (SE) } \\
\hline Biological father & $1.43(1.12)$ & $3.15(1.57)$ & $0.03(1.28)$ & $1.13(1.78)$ & $0.22(1.01)$ & $-1.56(1.45)$ \\
\hline Blended & $-0.32(0.94)$ & $0.71(1.55)$ & $3.45(1.32)^{* *}$ & $4.35(1.99)^{*}$ & $-0.07(0.91)$ & $-1.84(1.31)$ \\
\hline Multigenerational & $-1.24(1.06)$ & $-0.85(1.60)$ & $1.58(1.65)$ & $1.07(2.73)$ & $1.14(1.42)$ & $-0.75(2.25)$ \\
\hline \multicolumn{7}{|l|}{ Other demographics, $\beta$ (SE) } \\
\hline Child age & $-0.07(0.02)^{* *}$ & $-0.18(0.04)^{* *}$ & $-0.20(0.02)^{* *}$ & $-0.26(0.05)^{* *}$ & $0.01(0.02)$ & $0.01(0.05)$ \\
\hline Maternal age & & $0.58(0.40)$ & & $-0.02(0.49)$ & & $-0.18(0.45)$ \\
\hline Children in household & & $0.33(0.67)$ & & $0.48(1.01)$ & & $-0.62(0.74)$ \\
\hline Adults in household & & $0.47(0.69)$ & & $-0.27(0.75)$ & & $0.72(0.72)$ \\
\hline \multicolumn{7}{|l|}{ Socioeconomic status, $\beta$ (SE) } \\
\hline Mother employed & & $0.96(0.93)$ & & $0.49(1.20)$ & & $1.05(0.77)$ \\
\hline Family income $(\$ 1,000)$ & & $-0.05(0.06)$ & & $0.07(0.06)$ & & $-0.02(0.04)$ \\
\hline \multicolumn{7}{|l|}{ Parental socialization, $\beta(S E)$} \\
\hline Sees father & & $-0.17(0.99)$ & & $2.08(1.46)$ & & $-0.21(1.34)$ \\
\hline Feels close to mother & & $1.70(1.16)$ & & $0.30(1.03)$ & & $0.67(0.97)$ \\
\hline Spends time with mother & & $0.20(0.28)$ & & $0.03(0.32)$ & & $-0.26(0.29)$ \\
\hline Mother expects child to drop out & & $-0.15(0.13)$ & & $-1.86(0.98)$ & & $-0.27(1.34)$ \\
\hline \multicolumn{7}{|l|}{ Mother's mental health, $\beta(S E)$} \\
\hline Depressive symptoms & & $-1.60(0.46)^{* *}$ & & $0.59(0.52)$ & & $-0.92(0.39)^{*}$ \\
\hline Mastery & & $-0.41(0.47)$ & & $0.91(0.65)$ & & $0.23(0.45)$ \\
\hline \multicolumn{7}{|l|}{ Out-of-home contexts, $\beta$ (SE) } \\
\hline Neighborhood safety & & $0.16(0.37)$ & & $0.08(0.46)$ & & $0.14(0.32)$ \\
\hline \multicolumn{7}{|l|}{ Day care arrangements, $\beta(S E)$} \\
\hline Center-based child care & & $-1.24(0.87)$ & & $-2.49(1.11)^{*}$ & & $-0.93(0.90)$ \\
\hline Relative child care & & $0.04(1.06)$ & & $-0.91(1.27)$ & & $-1.27(0.96)$ \\
\hline Nonrelative child care & & $2.55(1.80)$ & & $-0.06(1.94)$ & & $0.99(1.16)$ \\
\hline$R^{2}$ & 0.01 & 0.04 & 0.05 & 0.09 & 0 & 0.02 \\
\hline Joint significance of living arrangements & 0.31 & 0.15 & 0.05 & 0.17 & 0.85 & 0.51 \\
\hline Hausaman test & 0.02 & & 0 & & 0.13 & \\
\hline Number of waves & 3,329 & 2,541 & 2,204 & 1,757 & 2,049 & 1,645 \\
\hline Number of individuals & 1,234 & 1,114 & 819 & 781 & 777 & 722 \\
\hline
\end{tabular}

$* p<.05 .{ }^{* *} p<.01$.

other covariates predict these outcomes in expected ways is reassuring. For example, maternal expectations of school failure strongly predict child outcomes as do maternal depressive symptoms. Nevertheless, outcome measures collected through other means (e.g., observer ratings) or other respondents (e.g., teachers) might reveal effects where none are apparent here.

Another possibility involves confounding not accounted for by our covariates or by fixed effects methods. For example, time-varying characteristics may influence both living arrangements and child outcomes. In this sample, living with a biological father may be associated with other unmeasured disadvantages. Perhaps, the father has entered or reentered the household because he has lost his job.
Of course, this possibility is reversed from what one typically suspects. Prior research is generally concerned that the advantages of living with one's biological father reflects other unobserved advantages (not disadvantages).

As noted above, another explanation for the absence of effects involves the nature of the fixed effects estimation. The effect of the living arrangement is identified by the association between changes in the outcome and in the explanatory variables of interest. If very few children experienced a change in living arrangement, the measured effect of that living arrangement would be identified by a few cases and would be imprecisely estimated as a result. However, a substantial number of children experience changes in living arrangements over time (Table 2). For 
example, 1,019 children transitioned in or out of a mother-only household during the study. Of those in a mother-only family at a given wave, $21 \%$ had moved into another family type by the next wave.

Likewise, if the outcome variables measure a trait that changes little over time, then the change in the outcome measure largely captures ephemeral variation. In that case, however, one would expect the outcome to have little or no association with any predictors. As noted, we do observe expected relationships.

Of course, another possibility is that living arrangements just do not matter much, at least for the very low-income families like those included in this study. Given that income differentials are hypothesized to explain up to half of the difference in child well-being in mother-only households versus two-parent households (McLanahan \& Sandefur, 1994), it is perhaps not surprising to find a more limited role for living arrangements in a sample with a very low and restricted range of income. The lack of statistical significance suggests that as much diversity exists within low-income families of a given type as across family types.

A final possibility is that living arrangements matter more for older children versus younger children. The importance of having a second caregiver to help monitor and supervise children's behavior, for example, could increase as children grow into adolescence and spend more time in the company of peers. Having two parents also could be important as children are making the transition to young adulthood, to the extent that such transitions have economic costs (i.e., the costs of postsecondary education) that are less easily borne by single mothers living alone.

\section{Implications for Research}

One interpretation of these findings is that increased attention to selection reduces the apparent (direct) effects of living arrangements. If future research confirms this finding, will the study of living arrangements and child outcomes be obsolete? We believe the answer is no. However, a shift in perspective may be warranted, perhaps especially for the study of low-income children's living arrangements. Research on racial differences in child outcomes is intertwined with that on living arrangements, and the former may offer a model for future research on the latter.

In particular, it may help think of differences across living arrangements as "disparities" of a sort. As with good research on racial differences, researchers understand that the apparent main effects of race and ethnicity often or even largely reflect the inability of the researcher to fully capture the determinants of child outcomes-they recognize that race per se plays little role as a main effect but that it is a proxy for key processes and inputs ignored or unmeasured. In that sense, it serves as a context for everything that occurs within the family, moderating the relationship between all inputs and key child outcomes.

One could argue that the effect of living arrangements could be conceptualized in a similar manner. If one believes that living arrangements are a proxy for key developmental forces, such as the absence of a male role model, then the answer is to measure those processes and not to speculate about residual differences among family types. Living arrangements are very likely more than a single input into the production of child outcomes-rather, they likely represent a different production process entirely. That process implies the availability of different inputs (such as the time inputs of a father) as well as the link between other inputs (such as time with a grandparent) and child outcomes.

Recent research on race and ethnicity emphasizes the role of within-group differences, and such research offers a second lesson for research on living arrangements and child outcomes. As noted above, the absence of large main effects in this low-income sample suggests that variation within family types is as great (or nearly so) as that across family types for this population. In that case, the key research question involves explaining that within-group variation. Conceptually, the question moves from "why do children from single-parent families fare worse than other children?", a question for which social science has provided clear and compelling answers (e.g., McLanahan \& Sandefur, 1994) to "what makes for successful development among low-income children within single-parent families?" and "are those factors the same across family types and for children in different race/ethnic groups?".

\section{Implications for Public Policy}

In light of these (non)findings, do living arrangement represent a promising means by which public policy can improve the lives of low-income children? The answer seems to be no. The direct effects of living arrangements (on average) are modest at best. As noted above, these analyses do not preclude family structure effects for some subgroups (not considered here) in some circumstances, but the overall effect of living arrangements is smaller and less consistent than that of other factors, such as maternal 
depression, a problem highly prevalent among lowincome mothers (Danziger et al., 2000).

Furthermore, even the effects captured here are likely mediated by still other factors not included in these analyses. Such mediation may explain the small size of the effects observed. Even if living arrangements have a robust effect on a mediator (e.g., 0.40) and the mediator has a robust effect on the developmental outcome (e.g., 0.40), the overall effect is still rather small $(0.16=0.40 \times 0.40)$. It is unclear that the mediation observed in a natural setting would occur if living arrangements were changed via public policy. Suppose, for example, that women who marry are able to move to better neighborhoods, providing their children with access to better schools. It is not clear that encouraging poor women in poor neighborhoods to marry will provide the same access.

The policy debate also is rather unclear as to "significant" for what purpose. Our results do not invalidate the use of living arrangements as a means of identifying at-risk children and youth. The key distinction, however, is that living arrangements may not be an effective target of intervention for very low-income children. This distinction implies rather different policies. The latter, for example, implies policies that eliminate or discourage single-parent families, the former, policies such as income support that assist such families in raising their children. Our results suggest that the second type of policy may be more effective in improving the well-being of lowincome children and youth.

\section{References}

Achenbach, T. M. (1978). The child behavior profile: I. Boys aged 6-11. Journal of Consulting and Clinical Psychology, $46,478-488$.

Achenbach, T. M., \& Edelbrock, C. S. (1979). The child behavior profile: II. Boys aged 12-16 and girls aged 6-11 and 12-16. Journal of Consulting and Clinical Psychology, 47, 223-233.

Aisenberg, E. (2001). The effects of exposure to community violence upon Latina mothers and their preschool children. Hispanic Journal of Behavioral Sciences, 23, 378-398.

Aquilino, W. S. (1996). The lifecourse of children born to unmarried mothers: Childhood living arrangements and young adult outcomes. Journal of Marriage and the Family, 58, 293-310.

Baca Zinn, M. (1994). Adaptation and continuity in Mexican-origin families. In R. L. Taylor (Ed.), Minority families in the United States: A multicultural perspective (pp. 64-81). Englewood Cliffs, NJ: Prentice Hall.
Battle, J. (2002). Longitudinal analysis of academic achievement among a nationwide sample of Hispanic students in one versus dual-parent households. Hispanic Journal of Behavioral Sciences, 24, 430-447.

Billingsley, A. (1992). Climbing Jacob's ladder: The enduring legacy of African-American families. New York: Simon and Schuster.

Brown, S. L (2004). Family structure and child well-being: The significance of parental cohabitation. Journal of Marriage and Family, 66, 351-367 (317).

Burton, L. (1996). The timing of childbearing, family structure, and role responsibilities of aging black women. In E. Hetherington \& E. Blechman (Eds.), Stress, coping, and resiliency in children and families (pp. 155172). Mahwah, NJ: Lawrence Erlbaum.

Bzostek, S., Carlson, M., \& McLanahan, S. (2007). Does mother know best? A comparison of biological and social fathers. Princeton University. Manuscript under review.

Chase-Lansdale, P. L., Brooks-Gunn, J., \& Zamsky, E. S. (1994). Young African-American multigenerational families in poverty: Quality of mothering and grandmothering. Child Development, 65, 373-393.

Chatters, L. M., Taylor, R. J., \& Jackson, J. S. (1985). Size and composition of the informal helper networks of elderly Blacks. Journal of Gerontology, 40, 605-614.

Conrad, K. J., Hultman, C. I., Pope, A. R., Lyons, J. S., Baxter, W. C., Daghestani, A. N., et al. (1998). Case managed residential care for homeless addicted veterans. Results of a true experiment. Medical Care, 36, $40-53$.

Danziger, S. K., Corcoran, M., Danziger, S. H., Heflin, C., Kalil, A., Levine, J., et al. (2000). Barriers to the employment of welfare recipients. In R. Cherry \& W. Rodgers (Eds.), Prosperity for all? The economic boom and African Americans (pp. 239-272). New York: Russell Sage Foundation.

Deleire, T., \& Kalil, A. (2002). Good things come in threes: Single-parent multigenerational family structure and adolescent adjustment. Demography, 39, 393-413.

Duncan, G., \& Brooks-Gunn, J. (Eds.). (1997). Consequences of growing up poor. New York: Russell Sage.

Dunifon, R., \& Kowaleski-Jones, L. (2002). Who's in the house? Race differences in cohabitation, single parenthood, and child development. Child Development, 73, $1249-1264$.

Dunn, L. M., \& Brooks, S. T. (1960). Peabody Picture Vocabulary Test performance of educable mentally retarded children. Training School Bulletin, 57, 35-40.

East, P., \& Felice, M. (1996). Adolescent pregnancy and parenting. Mahwah, NJ: Lawrence Erlbaum.

Edelbrock, C., \& Achenbach, T. M. (1980). A typology of child behavior profile patterns: Distribution and correlates for disturbed children aged 6-16. Journal of Abnormal Child Psychology, 8, 441-470.

Edelbrock, C. S., \& Achenbach, T. M. (1984). The teacher version of the child behavior profile: I. Boys aged 6-11. Journal of Consulting and Clinical Psychology, 52, 207-217. 
Edin, K., \& Kefalas, M. (2004). Promises I can keep: Why poor women put motherhood before marriage. Berkeley: University of California Press.

Entwisle, D., \& Alexander, K. (1996). Family type and children's growth in reading and math over the primary grades. Journal of Marriage and the Family, 58, 341-355.

Federal Interagency Forum on Child and Family Statistics. (2005). America's children: Key national indicators of wellbeing 2005. Federal Interagency Forum on Child and Family Statistics. Washington, DC: U.S. Government Printing Office.

Fortney, J., Booth, B., Zhang, M., Humphrey, J., \& Wiseman, E. (1998). Controlling for selection bias in the evaluation of Alcoholics Anonymous as aftercare treatment. Journal of Studies on Alcohol, 59, 690-697.

Foster, E. M., \& Bickman, L. (1996). An evaluator's guide to detecting attrition problems. Evaluation Review, 20, $695-723$.

Foster, E. M., \& Kalil, A. (2005). Developmental psychology and public policy: Progress and prospects. Developmental Psychology, 41, 827-832.

Furstenberg, F., Cook, T., Eccles, J., Elder, G., \& Sameroff, A. (1996). Managing to make it: Urban families and adolescent success. Chicago: University of Chicago Press.

Gage, G. E., \& Naumann, T. F. (1965). Correlation of the Peabody Picture Vocabulary Test and the Wechsler Intelligence Scale for Children. Journal of Educational Research, 58, 466-468.

Ganong, L., \& Coleman, M. (2004). Stepfamily relationships: Development, dynamics, and interventions. New York: Kluwer Academic Press.

Garcia-Coll, C., Lamberty, G., Jenkins, R., McAdoo, H., Crnic, K., Wasik, B., et al. (1996). An integrative model for the study of developmental competencies in minority children. Child Development, 67, 1891-1914.

Geronimus, A., Korenman, S., \& Hillemeier, M. (1994). Does young maternal age adversely affect child development? Evidence from cousin comparisons in the United States. Population and Development Review, 20, 585-609.

Glascoe, F. P., Foster, E. M., \& Wolraich, M. L. (1997). An economic analysis of developmental detection methods. Pediatrics, 99, 830-837.

Goldscheider, F. K., \& Bures, R. M. (2003). The racial crossover in family complexity in the United States. Demography, 40, 569-587.

Gorman-Smith, D., \& Tolan, P. (1998). The role of exposure to community violence and developmental problems among inner-city youth. Development and Psychopathology, 10, 101-116.

Greenfield, D. B., Iruka, I. U., \& Munis, P. (2004). Assessment of social competence in high-risk preschoolers: Evaluation of the adaptive social behavior inventory (ASBI) across home and school settings. Journal of Psychoeducational Assessment, 22, 220-232.

Greenfield, D. B., Wasserstein, S. B., Gold, S., \& Jorden, B. (1997). The adaptive social behavior inventory (ASBI): Evaluation with high-risk preschoolers. Journal of Psychoeducational Assessment, 15, 322-333.
Hall, S. M., Delucchi, K. L., Velicer, W. F., Kahler, C. W., Ranger-Moore, J., Hedeker, D., et al. (2001). Statistical analysis of randomized trials in tobacco treatment: Longitudinal designs with dichotomous outcome. Nicotine and Tobacco Research, 3, 193-202.

Haurin, R. J. (1992). Patterns of childhood residence and the relationship to young adult outcomes. Journal of Marriage and the Family, 54, 846-860.

Hawkins, A., \& Eggebeen, D. (1991). Are fathers fungible? Patterns of co-resident adult men in maritally disrupted families and young children's well-being. Journal of Marriage and the Family, 53, 958-972.

Hofferth, S. (2003). Race-ethnic differences in father involvement in two-parent families: Culture, context, or economy?. Journal of Family Issues, 24, 185-216.

Hofferth, S., \& Anderson, K. (2003). Are all dads equal? Biology versus marriage as a basis for paternal investment. Journal of Marriage and Family, 65, 213-232.

Hoffman, S. D. (2007). The socio-economic effects of teen childbearing re-considered: A re-analysis of the teen miscarriage experiment. Unpublished manuscript.

Hoffman, S. D., Foster, E. M., \& Furstenberg, F. F., Jr. (1993). Re-evaluating the costs of teenage childbearing. Demography, 30, 1-13.

Jargowsky, P. (1997). Poverty and place: Ghettos, barrios, and the American city. New York: Russell Sage Foundation.

Joint Center for Political and Economic Studies. (2004). Income and poverty among African Americans [Electronic version]. Retrieved August 1, 2004, from http:/ / www.jointcenter.org/2004election/CBC-health-briefs / Economic+Brief.pdf

Kalil, A., DeLeire, T., Jayakody, R., \& Chin, M. (2001). Living arrangements of single-mother families: Variations, transitions, $\mathcal{E}$ child development outcomes (Working Paper Series 01.20). Chicago: The University of Chicago.

Kaufman, J. C., Kaufman, A. S., Kaufman-Singer, J., Kaufman, N. L., Flanagan, D. P., \& Harrison, P. L. (2005). The Kaufman Assessment Battery for Children-Second Edition and the Kaufman Adolescent and Adult Intelligence Test. In D. P. Flanagan \& P. L. Harrison (Eds.), Contemporary intellectual assessment: Theories, tests, and issues (pp. 344-370). New York: Guilford Press.

Kreider, R., \& Fields, J. (2005). Living arrangements of children, 2001: Current population reports (pp. 70-104). Washington, DC: U.S. Census Bureau.

Leadbeater, B., \& Bishop, S. (1994). Predictors of behavior problems in preschool children of inner-city Afro-American and Puerto-Rican adolescent mothers. Child Development, 65, 638-648.

Lichtenberger, E. O., Kaufman, A. S., \& Bracken, B. A. (2000). The assessment of preschool children with the Kaufman Assessment Battery for Children. In B. A. Bracken \& R. J. Nagie (Eds.), The psychoeducational assessment of preschool children (3rd ed., pp. 103-123). Mahwah, NJ: Lawrence Erlbaum Associates.

Lichtenberger, E. O., Kaufman, A. S., \& Bracken, B. A. (2004). The assessment of preschool children with the 
Kaufman Assessment Battery for Children. In B. A. Bracken \& R. J. Nagle (Eds.), The psychoeducational assessment of preschool children (3rd ed., pp. 103-123). Mahwah, NJ: Lawrence Erlbaum Associates.

Lichter, D., \& Qian, Z. (2004). Marriage and family in a multiracial society. New York: Russell Sage Foundation.

Little, R. J. A., \& Rubin, D. B. (2002). Statistical analysis with missing data (2nd ed.). Hoboken, NJ: John Wiley and Sons.

Manning, W., \& Smock, P. (1997). Children's living arrangements in unmarried-mother families. Journal of Family Issues, 18, 526-544.

Mayer, S. E. (1997). What money can't buy: Family income and children's life chances. Cambridge, MA: Harvard University Press.

McLanahan, S. S., \& Sandefur, G. (1994). Growing up in a single parent family: What hurts, what helps. Cambridge, MA: Harvard University Press.

McLanahan, S. S., \& Teitler, J. (1999). The consequences of father absence. In M. Lamb (Ed.), Parenting and child development in non-traditional families. Mahwah, NJ: Lawrence Erlbaum.

McLoyd, V. C. (1998). Socioeconomic disadvantage and child development. American Psychologist, 53, 185-204.

Nelson, S., Clark, R., \& Acs, G. (2001). Beyond the twoparent family: How teenagers fare in cohabiting couple and blended families [Electronic version]. New Federalism: National Survey of America's Families, B-31. Retrieved August 6, 2002, from http://www.urban. org/publications/310339.html

Norris, R. C., Hottel, J. V., \& Brooks, S. (1960). Comparability of Peabody Picture Vocabulary Test scores under group and individual administration. Journal of Educational Psychology, 51, 87-91.

Orme, J. G., Reis, J., \& Herz, E. J. (1986). Factorial and discriminant validity of the Center for Epidemiological Studies Depression (CES-D) scale. Journal of Clinical Psychology, 42(1), 28-33.

Oropesa, R., \& Landale, N. (2004). The future of marriage and Hispanics. Journal of Marriage and Family, 66, 901-920.

Osborne, C., McLanahan, S., \& Brooks-Gunn, J. (2003). Is there an advantage to being born to married versus cohabiting parents? Differences in child behavior. Paper presented at the National Poverty Center Conference on Marriage and Family Formation among Low-income Couples, Washington, DC.

Pearlin, L. I., \& Schooler, C. (1978). The structure of coping. Journal of Health and Social Behavior, 19(1), 2-21.

Raley, R. K. (1995). Black-white differences in kin contact and exchange among never-married adults. Journal of Family Issues, 16, 77-103.

Raley, R. K., Durden, T. E., \& Wildsmith, E. (2004). Understanding Mexican-American marriage patterns using a life-course approach. Social Science Quarterly, $85,872-890$.

Ricciuti, H. (2004). Single parenthood, achievement, and problem behavior in white, black, and Hispanic children. Journal of Educational Research, 97, 196-206.

Rice, J. A., \& Brown, L. F. (1967). Validity of the Peabody Picture Vocabulary Test in a sample of low IQ children. American Journal of Mental Deficiency, 71, 602-603.

Roberts, R. E., \& Vernon, S. W. (1983). The Center for Epidemiological Studies Depression Scale: Its use in a community sample. American Journal of Psychiatry, 140, 41-46.

Shapiro, T. (2004). The hidden cost of being African American: How wealth perpetuates inequality. New York: Oxford University Press.

Sherman, A., Fremstad, S., \& Parrott, S. (2004). Employment rates for single mothers fell substantially during recent period of labor market weakness [Electronic version]. Retrieved August 1, 2004, from http://www. cbpp.org/6-22-04ui.htm

Smock, P. (2000). Cohabitation in the United States: An appraisal of research themes, findings, and implications. Annual Review of Sociology, 26, 1-20.

Stack, C., \& Burton, L. (1993). Kinscripts. Journal of Comparative Family Studies, 24, 157-170.

St.Pierre, R. G., Layzer, J. I., Goodson, B. D., \& Bernstein, L. S. (1997). National impact evaluation of the Comprehensive Child Development Program: Report to Congress. Cambridge, MA: Abt Associates.

Thompson, S. K. (1992). Sampling. New York: Wiley.

Unger, D., \& Cooley, M. (1992). Partner and grandmother contact in black and white teen parent families. Journal of Adolescent Health, 13, 546-552.

U.S. Department of Health and Human Services. (2006). Promoting responsible fatherhood: Federal resource site. Retrieved December 30, 2006, from http://father hood.hhs.gov/

Verbeek, M., \& Nijman, T. (1992). Testing for selectivity bias in panel data models. International Economic Review, 33, $681-703$.

Wherry, L., \& Finegold, K. (2004). Marriage promotion and the living arrangements of black, Hispanic, and white children. Washington, DC: The Urban Institute.

Wollack, J. A., Bolt, D. M., Cohen, A. S., \& Lee, Y.-S. (2002). Recovery of item parameters in the nominal response model: A comparison of marginal maximum likelihood estimation and Markov chain monte carlo estimation. Applied Psychological Measurement, 26, 339-352.

Wooldridge, J. M. (2002). Econometric analysis of cross section and panel data. Cambridge, MA: The MIT Press.

Wu, L. (1996). Effects of family instability, income and income instability on the risk of a premarital birth. American Sociological Review, 61, 386-404. 